\title{
GEOGRÁFICA DIGITAL
}

Revista del Instituto de Geografía de la UNNE

http://revistas. unne.edu.ar/index.php/geo

Revista Geográfica Digital, 2021, Vol. 1, No 35, 76-96 pp., E-ISSN: 1668-5180: DOI: http://dx.doi.org/10.30972/geo.18355135

\section{Experiencias económicas alternativas. Casos de economía social en sectores urbanos del Área Metropolitana del Gran Resistencia y la Provincia de Corrientes (2018-2019)}

\section{Alternative economic experiences. Cases of social economy in urban sectors of the Metropolitan Area of Gran Resistencia and the Province of Corrientes (2018-2019)}

\section{Bonfanti, Fernando A. ${ }^{1}$; Falcón, Vilma L. ${ }^{2}$}

1Departamento de Geografía. Facultad de Humanidades. Universidad Nacional del Nordeste (UNNE). fbonfanti1976@gmail.com ²Departamento de Geografía. Facultad de Humanidades. Universidad Nacional del Nordeste (UNNE).vfalcon_1609@hotmail.com

Palabras claves:

Economía Social

Economía social y solidaria

Trabajo

Resistencia

Corrientes
R e s u m e n

El presente artículo aborda temas referidos a la Economía Social retomando algunos de sus fundamentos teóricos e históricos e incluyendo casos particulares de actividades enmarcadas en esa línea temática. Las experiencias se desarrollan en sectores urbanos tanto del Área Metropolitana del Gran Resistencia (AMGR) como de la provincia de Corrientes y cada una de ellas presenta particulares trayectorias locales o regionales. Los diferentes casos ejemplificados han sido indagados en el marco de una investigación desarrollada con un grupo de alumnos siguiendo una metodología cualitativa mediante la realización de entrevistas, observación directa y trabajo de campo a través de las cuales se hicieron visibles las formas, modos y particularidades de una economía que, por su lógica de funcionamiento, se torna diferente a la del modelo dominante. Es así que este trabajo, orientado preferentemente a quienes se inician en la lectura de este tema, retoma algunos aspectos de esa indagación con el propósito de esbozar una aproximación teórica a la economía social y proveer ejemplos concretos de prácticas realizadas en nuestro medio, favoreciendo la comprensión de sus características esenciales tales como los valores, principios y lógicas que rigen su funcionamiento.

\section{A b s t r a c t}

Keywords:

Social Economy

Social and solidarity Economy

Work

Resistencia

Corrientes

This article addresses issues related to the Social Economy, taking up some of its theoretical and historical foundations and including particular cases of activities framed in this thematic line. The experiences are developed in urban sectors both in the Greater Resistencia Metropolitan Area (AMGR) and in the province of Corrientes, and each one of them presents particular local or regional trajectories. The different exemplified cases have been investigated within the framework of an investigation carried out with a group of students following a qualitative methodology by conducting interviews, direct observation and field work through which the forms, modes and particularities of an economy that, due to its operating logic, becomes different from that of the dominant model. Thus, this work, preferably aimed at those who are beginning to read this topic, takes up some aspects of that inquiry with the purpose of outlining a theoretical approach to the social economy and providing concrete examples of practices carried out in our environment, favoring the understanding of its essential characteristics such as the values, principles and logic that govern its operation 


\section{Introducción}

Durante los últimos años ha existido una notable presencia del debate sobre la economía social tanto en Latinoamérica como en Argentina donde, inclusive, se ha producido un gran número de estudios sobre diversas experiencias concretas vinculadas al tema las que, en general, fueron muy poco abordadas desde la disciplina geográfica.

El amplio espectro que abarca la economía social, también denominada a veces como tercer sector, economía solidaria, economía social y solidaria, economía popular, economía informal, economía del bien común, entre otros, ha sido incorporado recientemente -en forma específica- como parte del contenido temático de la asignatura Geografía Económica y Política General que se dicta en la carrera del profesorado y licenciatura en Geografía en la Facultad de Humanidades de la Universidad Nacional del Nordeste. En ese contexto, nos encontramos con un campo de estudio que incluía nuevas categorías de análisis, nuevas miradas o enfoques que se dan desde otras perspectivas -epistemológica e ideológica- de la Economía, cuestiones que consideramos necesarias incluirlas en el proceso de aprendizaje y preparación de los futuros docentes y licenciados de nuestras carreras. Consecuentemente, el progresivo reconocimiento de diversas experiencias de economía social y solidaria funcionando en la ciudad de Resistencia y en algunos centros urbanos de la provincia de Corrientes nos puso en contacto no solo con las prácticas mismas sino con una nueva forma de entender a la Economía que opera por fuera de los modelos tradicionales.

Sin duda, la diversidad de actividades que se desarrollan en el marco de la economía social muestra características distintivas entre sí, aunque muchas veces poseen atributos compartidos, por ejemplo cuando desarrollan actividades económicas con un fin social. En ocasiones presentan un carácter asociativo basado en una gestión democrática y solidaria en un contexto de total independencia, tanto del sector privado lucrativo como del Estado.

A pesar de no haber claridad en cuanto a las diferencias y las fronteras conceptuales, França Filho (2002) sugiere que esas organizaciones, independientemente de la terminología usada para clasificarlas, tienen en común el hecho de ocupar un espacio de vida social y de trabajo que está entre las esferas del Estado y del mercado (Battisti Telles et al., 2020).

Precisamente, el propósito de este texto es contribuir a la lectura, el pensamiento crítico, reflexivo de quienes se inician en la lectura de estos temas, especialmente dirigido a los futuros docentes e investigadores de nuestras carreras, favoreciendo el conocimiento referido a las ideas, conceptos y discusiones más relevantes que se dan alrededor de la economía social como categoría de análisis.

Por otra parte, el trabajo se sustenta en una práctica pedagógica que propone una construcción cooperativa del conocimiento que retroalimenta el proceso de enseñanza-aprendizaje dado que pone en juego determinadas estrategias didácticas que llevan al sujeto estudiante/investigador a:

- articular el conocimiento y la acción a partir del desarrollo de pequeñas investigaciones cuyo objetivo es ponerlo en contacto con la realidad social de la que forma parte;

- reconocer los diferentes modos de aproximarse al sujeto/objeto por conocer;

- seleccionar las herramientas metodológicas más adecuadas al proceso de indagación en una investigación social y, finalmente,

- compartir los resultados con sus pares y docentes para completar el circuito de interacción cognitiva

El proceso de "inter aprendizaje de la investigación" (Morales et al., 2005, p.2) contempla también la divulgación y comunicación de las evidencias logradas, posibilidad en la que intervenimos a través de este escrito. Precisamente, en este texto, los resultados obtenidos se constituyen en el insumo para describir los casos de economía social operando en nuestro medio.

En general, el artículo se organiza de la siguiente manera: en primer lugar se realiza un comentario acerca de los aspectos metodológicos seguidos en el marco de una investigación social de corte cualitativo; posteriormente y como parte del marco teórico se realiza una breve descripción acerca de los sectores en que se organiza la economía para luego incorporar distintas miradas acerca del concepto de economía social. Se describen, además, algunas cuestiones vinculadas a las políticas públicas que se han implementado para acompañar a este sector, tanto en el país como en las provincias de Chaco y Corrientes, espacios geográficos desde donde se recuperan las 22 experiencias locales que se describen con sus particulares formas organizativas, trayectorias y modos de dar respuestas a problemáticas de distinta índole. Seguidamente esbozamos algunas particularizaciones y agrupamientos basados en una propuesta teórica que tiene en cuenta el carácter colectivo o individual de la iniciativa, la figura jurídica que los nuclea y el grado de 
vinculación con el Estado. Finalmente exponemos algunas ideas a modo de conclusión.

\section{Materiales y métodos}

En relación a las cuestiones metodológicas el escrito presentado responde a un trabajo de carácter exploratorio que describe las particularidades de la economía social y sitúa en esa categoría a los casos concretos registrados en los resultados de una investigación desarrollada con un grupo de alumnos de la licenciatura en Geografía -ciclo articulación, sede Corrientes y del profesorado en Geografía de la Facultad de Humanidades de la UNNE, entre los años 2018 y 2019. En ese contexto, al tener como centro de estudio y análisis a un hecho social como lo es la economía en general y la economía social en particular, se trabajó en el marco de una investigación social de corte cualitativo entendiendo, como lo señala Vasilachis (2009, p.28), que desde ese marco "la investigadora o el investigador cualitativos se aproximan a situaciones, acciones, a procesos, a acontecimientos reales, concretos, a interacciones espontáneas (...). Los investigadores observan, analizan esas situaciones, esos procesos, sucesos y/o sus consecuencias y tratan de captarlos tan completamente como les sea posible...", aspectos que formaban parte de los objetivos y actividades de la propuesta didáctica investigativa en los espacios curriculares mencionados. La autora también sostiene que una investigación de tipo cualitativa "es interpretativa, inductiva, multimetódica y reflexiva (...) emplea métodos de análisis y de explicación flexibles y sensibles al contexto social en el que los datos son producidos (Vasilachis, 2009, p.29). La búsqueda de materializar esas particularidades es el fundamento de la práctica pedagógica asumida en la que se parte de la idea de enseñar a investigar investigando, en contextos reales y con problemas sociales del propio entorno del investigador.

El método más apropiado para aproximarnos a los Sujetos de la economía social fue el estudio de caso. Al respecto, Sautu, R. (2005, p.78) señala que "el estudio de caso está generalmente asociado a la tradición sociológica, a los estudios rurales y a la investigación de organizaciones en economía...." y en este trabajo, precisamente, las organizaciones de la economía social se constituyeron en el centro del estudio y por lo tanto en "el caso" considerado de interés. Como lo señala la autora, "la adopción de este método requiere diferenciar los límites de su entorno para establecer qué constituye un caso" (op.cit) y en ese sentido nuestra primera delimitación se basó en la diferente concepción epistemológica e ideológica de la economía clásica, tradicionalmente estudiada en nuestra carrera, respecto de la "otra economía", "economía alternativa" o economía social como la denominamos en este texto. La lectura y análisis de textos fueron los recursos utilizados en ese proceso de construcción teórica de la categoría 'economía social' hasta lograr identificar el caso particular (organización y/o emprendimiento) que se localizara en la ciudad o espacio próximo al lugar de residencia de cada integrante de la investigación.

Identificado el caso específico, es decir la organización o experiencia de economía social, se diseñaron las estrategias más apropiadas para construir las evidencias empíricas de este estudio; es así que se recurrió al trabajo de campo, la observación directa y a la aplicación de entrevistas como técnicas a utilizar. En este punto debemos considerar que la Unidad de análisis quedó conformada por la 'organización y/o emprendimiento' y la unidad de recolección de datos por los 'individuos' que brindaron la información que requería el estudio (Vasilachis, 2009, p.87). La entrevista dialógica fue considerada el instrumento técnico más apropiado para llevar a cabo el proceso de construcción de evidencias; en ese sentido optamos por la aplicación de entrevistas semi-estructuradas, incluyendo en el diseño algunas líneas o ejes principales alrededor del cual giraban los principales aspectos que se intentaban recuperar a partir del dialogo con las personas entrevistadas; las grabaciones, anotaciones y registros fotográficos formaron parte de los recursos utilizados en el proceso. De esta manera se logró identificar y describir las formas, modos, lógicas de funcionamiento de algunas prácticas de economía social desarrolladas por individuos o grupos de personas que residen en el Área Metropolitana del Gran Resistencia y en localidades de la provincia de Corrientes.

Cabe advertir que en este escrito fueron incluidos 22 ejemplos de economía social recuperados de los trabajos que cumplieron con todo el proceso de investigación, desde la identificación teórica de la categoría, el diseño del instrumento de recolección de información, la realización de las entrevistas y presentación de los resultados. Sabemos que estos ejemplos son aún escasos para lograr una descripción sistemática y global del funcionamiento de la economía social en la región, por lo cual debe tomarse este texto como un aporte inicial que pretendemos seguir fortaleciendo con sucesivas investigaciones de esta índole. 


\section{Marco Teórico}

\subsection{La economía como centro de interés y la organización según sectores}

Partimos de la idea de que la sociedad se organiza para dar respuestas a múltiples necesidades y decisiones que tienen que ver con el proyecto y opción de vida de las personas, entre las cuales el aspecto económico es una parte esencial en ellas. En efecto, las actividades económicas son un conjunto de acciones pensadas y llevadas a cabo por los seres humanos para satisfacer sus necesidades -en sentido amplio- y algunas veces son resueltas por la sociedad privada mercantil (empresas en una diversidad de formas) 0 por la sociedad política (Estado) también en su diversidad y complejidad, o bien, por las familias (economía doméstica). Pero no todas las actividades económicas que desarrollan las personas se dan exclusivamente en estos ámbitos o esferas; hay una amplia gama de formas organizativas cuya esencia, modalidad, destino, objetivos y propósitos difieren y, a la vez, otorgan diferentes características de funcionamiento respecto de aquellas otras formas o prácticas de esencia mercantil-capitalista o de actuación estatal; son las que conforman la economía social, sobre cuyo concepto nos referiremos más adelante.

A grandes rasgos, en la Figura 1 se representa la organización de los sectores según el interés económico de la sociedad.

Figura 1. El interés económico y la organización de la Sociedad.

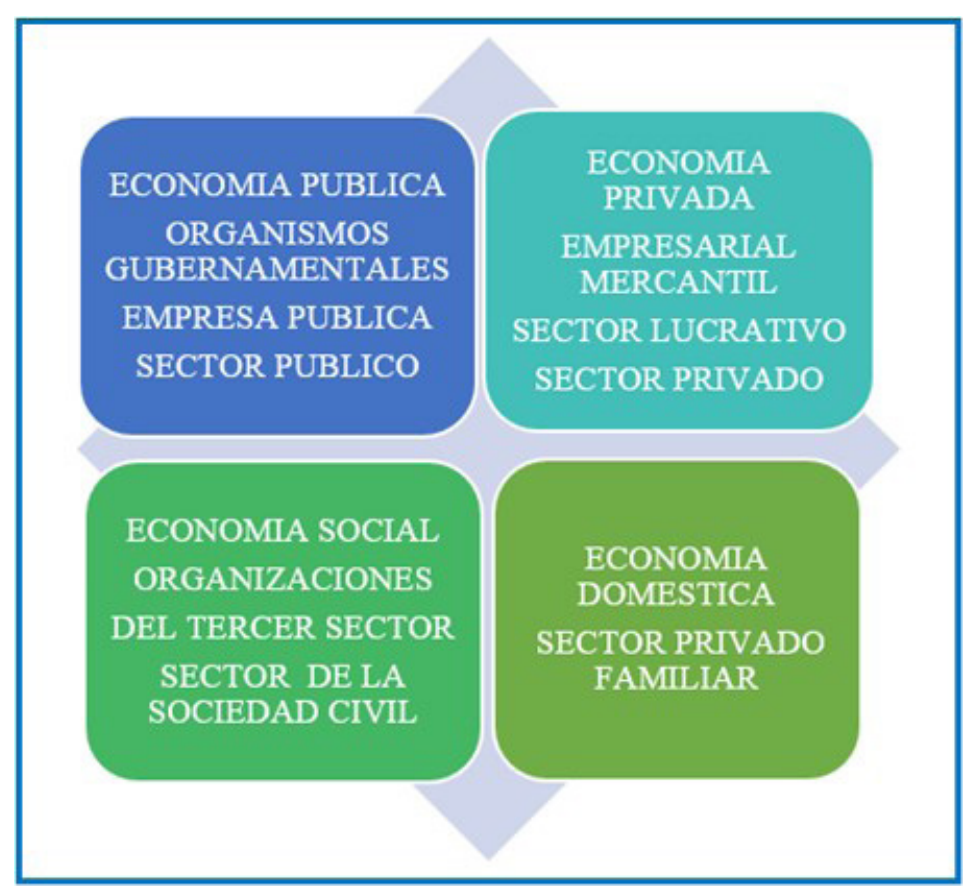

Fuente: elaboración propia basada en la interpretación de los autores. en la Figura 1:

En una breve caracterización podemos señalar algunas particularidades de cada sector representado

El sector privado es aquel que se rige por lógicas mercantilistas - capitalistas, es decir que su propósito o fin es el lucro o la obtención del máximo beneficio; si bien no está controlada por el Estado cumple con las regulaciones impuestas por él. Las formas jurídicas en que se pueden desarrollar las actividades económicas del sector privado son muy variadas y van desde el ejercicio individual de una actividad empresarial hasta las grandes compañías que cotizan en bolsa y son propiedad de miles de accionistas, pasando por otras formas como la sociedad de responsabilidad limitada, la comunidad de bienes, la unión temporal de empresas, etc.

El sector público hace hincapié en el Estado, que interviene en el desarrollo de la actividad económica como consumidor y como productor. Así, actúa como unidad económica de consumo cuando adquiere bienes y servicios de las empresas privadas (nacionales o extranjeras) para desarrollar funciones y objetivos específicos. Por otro lado, actúa como unidad económica de producción a través de las empresas públicas que producen bienes y prestan servicios de interés público (infraestructuras, enseñanza, sanidad). Las funciones que se le asignan al sector público en una economía mixta son las de fomentar la eficiencia 
económica, mejorar la distribución del ingreso, propiciar la estabilidad y el crecimiento económico.

El sector de la Sociedad Civil (SC) es aquel que lleva adelante actos y prácticas económicas y tienen también propósitos de actividad mercantil, dada la búsqueda de la eficiencia en la gestión y el beneficio de las actividades emprendidas. Se distingue de las otras formas lucrativas porque en esencia, sus objetivos o fines tienen que ver con el interés colectivo o general, con la solidaridad o el altruismo y en lo organizativo brega por la participación, la responsabilidad y la cooperación. Se corresponde con lo que, desde la mirada europea, forma parte del Tercer Sector Social. Según la forma en que se dan las relaciones sociales en el proceso económico que lleva a cabo la sociedad civil, se redimensionan y redefinen los parámetros sociales que caracterizan a los otros sectores o sistemas de la sociedad.

Según Defourny (2001, p.4) la caracterización “tercer sector" es la denominación que suscita el mayor consenso entre los científicos del ámbito. Específicamente entre las denominaciones del tercer sector dos se afirman fuertemente en el ámbito internacional: economía social (o solidaria) y sector non profit (Oxoby, 2010).

La 'economía social' tiene la característica específica de producir bienes, servicios y conocimiento a la vez que persigue objetivos tanto económicos como sociales y promueven la solidaridad, de allí que también se la denomine economía solidaria. Se corresponde con la vertiente empresarial, pues en algunos casos existe cierto ánimo de lucro para subsistir.

Por su parte, la 'economía no lucrativa' incluye a las organizaciones sin fines de lucro (non profit organizations), al sector voluntario, a los sectores filantrópicos, a las entidades caritativas, Organizaciones no gubernamentales (ONGs), y a sectores exentos de impuestos que tratan de resolver problemas más integrales que los estrictamente productivos. El término 'no lucrativo' subraya la característica de inapropiabilidad de los excedentes o beneficios de la entidad u organización por parte de los individuos que forman parte del control de ella. El propósito de la actividad que desarrollan no es el de la multiplicación del capital sino el de lograr algún tipo de finalidad social, en sentido de la cooperación entre personas y de las mejoras en la calidad de vida general. Estas organizaciones se sostienen económicamente a partir de un capital (puede ser mínimo o manejar grandes montos de acuerdo con la envergadura de la misma) que provienen -en general- de donaciones realizadas por personas físicas o empresas. Para incluir una entidad en este sector debe cumplir dos requisitos: la finalidad social y el no reparto de beneficios (sin ánimo de lucro). Los ejemplos van desde Organizaciones religiosas, bomberos voluntarios, hasta los comedores o merenderos barriales, pasando por centros, fundaciones o asociaciones que intentan dar respuestas a situaciones problemáticas de personas vulnerables.

Finalmente, en cuanto a la 'Economía Doméstica', existe consenso en afirmar que la familia es la institución preexistente a las otras formas de organización social Mercado-Estado, ya que desde el seno de aquella surgieron las primeras formas de resolver los problemas económicos.

\begin{abstract}
"al navegar por la etimología de la palabra economía encontramos que esta proviene de las raíces griegas "oikos" y "nomo", que significan la forma de organizar la casa. Se trata pues de resolver los problemas que existen en la casa, en la morada, en el hogar, en la sociedad. (sic) Por los miembros de la familia, a través de la utilización de los mejores medios de que se disponga: programando adecuadamente "el trabajo de todos"; distribuyendo equitativamente el fruto del trabajo común; aceptando las reglas de justicia emanadas de la autoridad paterna, de por sí competente y compasiva; resolviendo las disputas por medio del diálogo que garantice el derecho de todos por igual. Acercándose, pues, al concepto de democracia practicada en familia, tal como la entendieron los griegos. Lo expuesto explica la aseveración de que no fue el mercado el lugar primigenio donde los primeros humanos organizados resolvieron sus problemas económicos" (Valencia Vásquez, 2006, p.23).
\end{abstract}

Ahora bien, para centrarnos en la cuestión que nos compete, partimos de la idea de que la economía es en esencia 'social', lo que cambia con las diferentes miradas es el eje alrededor del cual gira el propósito final del acto económico. Cuando hablamos de Economía y reconocemos a los factores clásicos de la producción económica (tierra, capital y trabajo), resulta necesario identificar la perspectiva epistemológica e ideológica desde la cual se la aborda porque será desde ese lugar-diferente a la de otros- que se concibe, comprende, aprehende y analiza el acto o hecho económico.

Así por ejemplo, para el liberalismo económico y la doctrina de lógica capitalista, el capital ocupa un lugar central y sus valores se rigen por el principio de la competencia, del máximo beneficio, del individualismo y del intercambio en un único escenario: el mercado; mientras que desde las ideologías y perspectivas más próximas al socialismo se considera una economía donde el eje central ya no es el capital sino el trabajo de las personas, realizado en un intercambio con el entorno social y natural; donde 
los valores -diferente al capitalismo- se basan en la solidaridad, la cooperación, la búsqueda del bien comunitario, entre otros principios.

Teniendo en cuenta lo anterior, en los párrafos que siguen, esbozamos el proceso de construcción y evolución teórico-conceptual de la economía social en el mundo y en Latinoamérica; al mismo tiempo que se enuncian algunas de las políticas públicas orientadas a este sector, tanto de Argentina en general como de las provincias de Chaco y Corrientes en particular.

\subsection{El concepto de economía social}

La "economía social" como campo de discusión académico tiene su punto de partida en el siglo XIX en Europa. No es casual que esta discusión se gestara conjuntamente con el desarrollo y la hegemonización del sistema capitalista como modo de acumulación imperante dado que las prácticas asociadas a este campo y, en general, los teóricos de la época, comenzaban a ver los efectos devastadores que traería consigo el desarrollo de este sistema (Lazarini, 2008, p.22).

Probablemente fue en 1830 que el término economía social apareció en la literatura económica, cuando el economista liberal francés Charles Dunoyer publicó el “Tratado de economía social” que defendía un enfoque moral de la economía (Borge y Li, 2015). Mencionando a Guerra (2012, p.3), Borge y Li (2015, p.4), señalan que el Tratado de Duyoner:
"se constituye en la primera piedra para la construcción de un concepto que empieza a dar a las personas un espacio en medio del liberalismo exacerbado del momento y que piensa en las diversas organizaciones constituidas por las clases trabajadoras para satisfacer de forma asociativa sus crecientes necesidades en un contexto de fuerte ascendencia del mercantilismo".

Las ideas marxistas y de los socialistas utópicos como Robert Owen, Henri de Saint Simon y Charles Fourier (en el período 1820/1840) fueron las que sentaron las bases fundamentales del cooperativismo; sin embargo, la primera aparición de dicho concepto en estudios económicos se remonta específicamente a partir de 1860 y fue, según Pérez de Mendiguren et al. (2008) gracias a la influencia de dos grandes economistas, John Stuart Mill y Leon Walras, quienes apodaron con tal término a las innovadoras organizaciones que se iban creando como respuesta a los nuevos problemas sociales que la incipiente sociedad capitalista generaba. Pero más allá de ser un instrumento para la denominación, Walras consideraba a la economía social como parte sustancial de la ciencia económica, como disciplina económica para la cual la justicia social era un objetivo ineludible de la actividad económica. Se puede decir que la economía social aglutinaba en su seno principalmente a tres entidades: cooperativas, mutualidades y asociaciones que tradicionalmente han sido consideradas como el núcleo duro de la economía social.

La tradición asociacionista se considera propia del movimiento revolucionario francés de 1848 , movimiento que respondió no solo a factores políticos e ideológicos sino también a descontentos económicos y sociales de la población en aquella época. Se buscaba fundamentalmente que la asociación obrera conserve los ideales de democracia, de esa forma, las cooperativas surgieron como formas de asociación de capital centradas en las funciones de producción y consumo, en tanto que las mutuales se concentraron en la función de seguro.

En la Europa del siglo XX, fundamentalmente después de períodos de crisis entre los '70 y '80 se ha comenzado a utilizar de forma frecuente el término hibrido economía social y solidaria para abarcar a las organizaciones de transformación social y de carácter solidario. En ese contexto histórico, uno de los teóricos más destacados fue el sociólogo francés Jean-Louis Laville. Definió a la Economía Solidaria como "el conjunto de las diversas actividades económicas (mercantil, no mercantil y no monetaria) que contribuyen a la democratización de la economía a partir del compromiso de los ciudadanos" (Laville, 2001, p.85).

En América Anglosajona, la concepción de la economía social quebequense se asocia con el surgimiento de una nueva economía social, que según Neamtan (2002):

"se diferencia de la vieja economía social (la de las cooperativas financieras, las sociedades mutuales y las grandes cooperativas de producción agraria) en que agrupa a muchos tipos de entidades y empresas con lógica de emprendimiento colectivo y acción comunitaria independiente que operan en nuevos sectores" (Pérez de Mendiguren y Etxezarreta, 2015, p.135).

Con esta mirada, el mismo Neatman (2002) define a la economía social como: 


\begin{abstract}
"un movimiento de transformación social que busca la democratización y el desarrollo de una economía de la solidaridad (...). Al mismo tiempo es un movimiento estratégico que busca desplegar su acción en el corazón de una economía mixta (plural) que combina las actividades del mercado, del Estado y de la sociedad civil (...). La economía social y solidaria cuestiona explícitamente los presupuestos y certezas de la visión neo-liberal de la economía" (Pérez de Mendiguren y Etxezarreta, 2015, p.136).
\end{abstract}

La economía social representa la búsqueda de alternativas a los servicios estatales y respuestas a las demandas insatisfechas por el Estado, en donde predominan iniciativas vinculadas al ámbito social y el desarrollo económico, en donde las iniciativas surgen como respuesta a la crisis del trabajo, - demandas para trabajar de otro modo - los individuos buscan crear su propio empleo (Mutuberría Lazarini, 2008).

La tradición latinoamericana recoge parte de la perspectiva acerca de la economía social surgida en Europa (dada la fuerte inmigración europea en nuestra región y su impacto cultural), a la vez que integra la conceptualización de prácticas sociales que responden a nuestra propia realidad e historia económica y social.

Una de las raíces que marcó fuertemente el inicio de la economía social (y solidaria) en Latinoamérica ha sido la corriente conocida como Teología de la Liberación, surgida en Brasil en la década de los 60's como una opción ética para la gente que se encontraba en situación de pobreza. A partir de esto, empezaron a generarse estrategias locales para el desarrollo del campo, donde posteriormente serán fundamentales las propuestas de educación popular impulsadas por Paulo Freire. Tiempo después estas ideas se expandieron hacia Perú, Venezuela, Guatemala, Cuba y otros países. La expresión 'economía solidaria' comenzó a ser más utilizada a principios de la década del '80, teniendo como principal representante al sociólogo chileno Luis Razeto.

Al inicio de los '90 comenzaron a implementarse en la región, una serie de políticas neoliberales que al finalizar la década arrojaron como resultado, un aumento en los niveles de pobreza, desempleo, precarización laboral, aumento de las desigualdades distributivas y desarticulación de las cadenas productivas, generando conflictos sociales. Es en este contexto en que la economía social y sus emprendimientos cobran protagonismo, en primera instancia como una respuesta espontánea desde la sociedad misma en pos de la satisfacción de necesidades imperiosas, no resueltas por el mercado o por el Estado y, luego en una segunda instancia, desde el ámbito gubernamental que decide acompañar esta iniciativa social por medio de diversos programas y políticas públicas (Oxoby, 2010). Las nuevas prácticas económicas que fueron emergiendo desde los sectores más postergados, adquirieron denominaciones distintas que daban cuenta de realidades sociales con cualidades similares: 'economía social', 'economía solidaria', 'economía social y solidaria', 'socioeconomía de la solidaridad', 'economía comunitaria', "economía popular de la solidaridad”, entre otros. Con esto se advierte que no es un concepto unívoco, sino polisémico, que representa un campo teórico en construcción, y cuyos grandes exponentes de la corriente latinoamericana son José Luis Coraggio (Argentina), Paul Singer (Brasil), Luis Razeto (Chile), Pablo Guerra (Uruguay), Boris Marañón (México), Bastidas Delgado (Venezuela), entre otros.

La gran mayoría de los conceptos mencionados en el párrafo anterior son abordados por José Luis Coraggio en sus trabajos, quien considera a todos ellos como la Otra Economía, una economía alternativa al modo capitalista. Asimismo defiende el término ‘Economía del Trabajo', que es una economía que produce sociedad y no sólo utilidades económicas, buscando satisfacer las necesidades de los mismos productores o de sus comunidades (necesidades de base territorial, étnica, social o cultural, además de la económica) y no está orientada por la acumulación de capital sin límites. Además, tiene como fundamento relaciones sostenibles de producción y reproducción y el trabajo y el conocimiento encarnado en los trabajadores y sus sistemas de organización (Coraggio, 2002).

La economía social es una forma alternativa de hacer economía, basada en la solidaridad y el trabajo, generando beneficios sociales y culturales que benefician a la sociedad, a través de experiencias prácticas y de teorías científicas; que incluyen el desarrollo humano, sostenible y con énfasis local (Razeto, 2010). Cabe advertir que este autor utiliza en la mayoría de sus trabajos la denominación economía de la solidaridad.

El profesor e investigador uruguayo Pablo Guerra se centra más en la expresión economía de la solidaridad, sobre todo con el propósito de revitalizar el pensamiento comunitarista frente al avance del neoliberalismo e individualismo, y señala que la misma hace referencia a "experiencias y comportamientos económicos que por sus lógicas, racionalidades, e instrumentos concretos de gestión, se distinguen tanto de la economía privada capitalista, como de la economía estatal” (Guerra, 2006, p.28). La considera como un modelo alternativo al capitalismo, que comprende un conjunto de iniciativas populares y/o 
comunitarias de hacer economía en todas sus expresiones (producción, consumo, distribución, ahorro), fuertemente asociada al cambio social; por ende constituye un fenómeno socioeconómico que comprende tres dimensiones distintas: el movimiento social; el paradigma científico; y, el sector específico de nuestras economías de donde convergen las distintas experiencias de base solidaria (Guerra, 2010).

Esta economía social tal como reaparece a fines del Siglo XX:

"es una respuesta al estrangulamiento financiero del desarrollo, a la desregulación de la economía y a la liberación de los movimientos del capital, que conllevan en diversos países, al desempleo en masa, cierre de firmas y creciente marginalización de los desempleados crónicos y de los que saben que no tienen posibilidad de volver a encontrar trabajo debido a la edad, falta de calificación o de experiencia profesional, discriminación de raza o género, etc." (Singer, 2004, p.199).

A través de sus principios, prácticas y valores relacionados con la participación, la democracia y la solidaridad, y sus objetivos sociales y muchas veces ambientales, la economía social ha demostrado ser resiliente frente a las crisis económicas. Cuando aumentan las desigualdades, la degradación ambiental, y la turbulencia económica general, la economía social brinda a la sociedad civil los medios necesarios para satisfacer sus necesidades. De hecho, la economía social proporciona bienes y servicios acordes con la realidad, la cultura y las necesidades de la comunidad a la que sirve (Borzaga et al., 2018).

Nuestra posición al respecto es considerar a la economía social como a un conjunto de mecanismos sociales impulsados desde la sociedad civil y que adoptan formas contractuales para intentar resolver las brechas entre las aspiraciones y necesidades no satisfechas, por una parte, y las reglas económicas institucionalizadas que prevalecen en una sociedad, por la otra.

Son promotores de los siguientes principios: democracia, propiedad y patrimonio colectivo, solidaridad, autonomía, ciudadanía. Entre sus formas organizativas se destacan: cooperativas, emprendimientos comunitarios, empresas recuperadas por los trabajadores, micro emprendimientos familiares, mutuales, espacios de trueque, ferias populares, redes de comercio justo o solidario, espacios de compra conjunta, microcrédito y banca social, instituciones que promueven la incubación de empresas, espacios culturales territoriales y sindicatos de trabajadores ocupados o desocupados (Roitman, 2016).

Todos ellos forman parte de experiencias que conviven, interactúan e imponen condiciones a la economía capitalista y al Estado, donde los actores sociales colectivos se van constituyendo en el mismo proceso, van interactuando y van construyendo poder popular.

\title{
3.3. La economía social en la Argentina. Breve repaso de la institucionalidad del sector
}

En el caso particular de la Argentina, los fenómenos socio-económicos enmarcados en la economía social son muy diversos y se caracterizan por su pluralidad; en ese sentido se afirma que:

\begin{abstract}
"dicho conjunto abarca una diversidad de experiencias, organizaciones $y$ emprendimientos que tienen características distintivas entre sí, pero (...) poseen una matriz identitaria de atributos compartidos, entre los que se destaca el desarrollar actividades económicas con una definida finalidad social (...) a la vez que implican elementos de carácter asociativo y gestión democrática en un contexto de autonomía tanto del sector privado lucrativo como del Estado" (Pastore, 2010, p.48).
\end{abstract}

Este hecho no quita que las relaciones con las otras esferas -especialmente públicas- sean mucho más marcadas que las que usualmente se cree, pues algunos de los hechos que sobresalen en esa relación son: el recibimiento de subsidios, asistencia técnica, capacitaciones, etc.

De este modo, y a grandes rasgos, la definición de la economía social se compone de tres grandes ramas. Por un lado, las cooperativas y mutuales, que son lo más clásico o tradicional, implicando otra forma de organización interna y de distribución de la riqueza. En segundo lugar, las empresas recuperadas, como una modalidad bastante novedosa, propiamente argentina. Por último, todo el mundo del emprendedurismo del autoempleo, tanto los individuales como los asociativos, incluyendo gasistas, plomeros, cuentapropistas y todos aquellos que emprenden una actividad productiva (Arroyo, 2006).

La grave crisis social y económica que atravesó la Argentina en el año 2001 dejó muchas secuelas marcadas en la sociedad, quizá una consecuencia más que visible se dio en el 2002 cuando se alcanzó el máximo nivel de pobreza (equivalente al 54,3\% de la población), así como también un alto nivel de desempleo (21,5\% de la PEA) y subocupación (18,6\% de la PEA) según el INDEC. En el extremo inferior del espectro social, asomaron las nuevas experiencias de organización a través de los movimientos piqueteros, 
que de a poco lograron afincarse territorialmente organizando a los desocupados de los barrios más carenciados y de las villas miserias o asentamientos.

Se necesitaba una reestructuración que permitiese mejorar dicha situación en el corto plazo. Es así como, con el gobierno que se inicia en 2003, el Estado comienza a dar respuestas con la implementación de políticas públicas para la economía social y solidaria (al igual que en otros países latinoamericanos), dirigidas específicamente a la población más vulnerable que ha sufrido desocupación o a aquellos que quedaron en situación de pobreza y exclusión. El objetivo de las mismas fue en principio promover el trabajo asociativo como forma de incidir en la reproducción de la vida.

El exponente más destacado de estas intervenciones estatales ha sido el Plan Nacional de Desarrollo Local y Economía Social 'Manos a la Obra', implementado por el Ministerio de Desarrollo Social a partir del año 2003. Nació con la idea de financiar proyectos productivos que favorezcan la inclusión social a partir de las distintas experiencias, oficios, recursos y habilidades de la gente y de las características propias de cada municipio y localidad; destinado a grupos de personas organizadas en forma asociada que necesiten trabajo y tengan una alternativa laboral que estén llevando adelante o necesiten apoyo para empezar (Hintze y Deux, 2008); en todos los casos se intentaba promover el trabajo para obtener ingresos y satisfacer necesidades básicas, dejando de lado el asistencialismo tradicional.

Desde un principio, las intervenciones típicas, según Daniel Arroyo (2006), han comprendido:

"la entrega o gestión de subsidios, capacitación, asistencia técnica, tutorización, etc, con la finalidad de fomentar el trabajo asociativo como forma de autogeneración de ingresos, promoviendo emprendimientos destinados a la venta de bienes y servicios en el mercado, $y$ en algunos casos, a finalidades no mercantiles (de autoconsumo o cuidado comunitario por ejemplo). Con magnitudes y complejidades muy diversas, sus programas comprenden desde el apoyo a emprendimientos mercantiles de pequeños grupos hasta cooperativas, empresas o redes de empresas autogestionadas por los trabajadores" (Hintze y Deux, 2008, p.2-3).

La implementación del Monotributo Social en 2004 también fue importante porque se procuró avanzar en la formalización de los emprendimientos para que puedan facturar, acceder al sistema jubilatorio y de obras sociales. En 2006 se promulgó la Ley 26.117 de "Promoción del Microcrédito", puesta en práctica por la Comisión Nacional de Microcrédito (Conami) con el objeto de facilitar el acceso crediticio del sector. Asimismo, en 2008 se promulgó la Ley 26.355, de "Marca Colectiva", con la finalidad de mejorar la identidad y valor agregado del sector. También se debe resaltar la promoción de las cooperativas de trabajo desde el 2003, primero con el Programa Federal de Emergencia Habitacional, y luego ampliado significativamente a otros programas. En efecto, a partir de esas experiencias, en 2009 se crea el Programa Ingreso Social con Trabajo "Argentina Trabaja", desde el cual se ejecutaron obras de infraestructura, equipamiento urbano o saneamiento ambiental en comunidades locales. De manera complementaria en 2013 se creó el Programa "Ellas Hacen", con la idea de incorporar a otras 100 mil mujeres en el trabajo cooperativo. Es de destacar que existe un debate abierto sobre este tipo de programas, en relación a sus capacidades efectivas para desarrollar experiencias de autogestión sostenibles en el tiempo, teniendo en cuenta el marco de complejos entramados de relaciones de poder territorial en el que se insertan. Todas estas políticas de intervención social interpelan a los sujetos desde valores y prácticas vinculadas a la producción asociada, el cooperativismo y la autogestión. (Pastore y Altschuler, 2015). Finalmente, en el año 2016 se lanzó el Plan Nacional de Economía Social "Creer y Crear", una continuidad de la política anterior que está destinada a financiar con la entrega de microcréditos, herramientas, insumos o generación de nuevos espacios de comercialización a emprendimientos productivos y actividades regionales.

Además de todo lo nombrado anteriormente, existieron otras instancias de institucionalización entre las que figuran: la creación de la Secretaría de Economía Social y Desarrollo Local (luego Secretaría de Economía Social); la integración del Instituto Nacional de Asociativismo y Economía Social (INAES), encargado de legislar, controlar y promocionar Cooperativas y Mutuales; la creación del Registro Nacional de Efectores de Desarrollo Local y Economía Social que identifica individualmente a los microemprendedores sociales en condiciones de vulnerabilidad social; la expansión de iniciativas en marcha o creación de dispositivos ligados con la pequeña producción agraria, tales como el Programa Pro-Huerta del Instituto Nacional de Tecnología Agropecuaria (INTA), el Programa Social Agropecuario (PSA) del Ministerio de Agricultura y el Centro de Investigación y Desarrollo Tecnológico para la Agricultura Familiar-INTA, con el objetivo de ampliar y promover la organización autogestionada de la pequeña agricultura familiar; la creación de diversos programas de capacitación y asesoría a cargo del Instituto de Tecnología Industrial (INTI) y el Ministerio de Trabajo, Empleo y Seguridad Social, dirigidos a nuevos emprendimientos de trabajadores autogestionados; la sanción de modificaciones a la Ley de Concursos y Quiebras, mediante la eliminación de la excepcionalidad en la recuperación de la empresa por parte de sus trabajadores así como 
otras garantías para los mismos, entre otras (Coraggio, 2014).

En estos últimos años, también se expandieron proyectos centrados en la formación de valores solidarios y orientados a la capacitación en oficios, técnicas y saberes implementados desde universidades populares hasta algunas escuelas de gestión social. Aun así, no se ha alcanzado un nivel de autonomía financiera en el común de sus emprendimientos (Blasco y García, 2016). En muchos casos, los emprendimientos asociativos se exponen a las crisis recurrentes que caracterizan al modo de producción capitalista, agudizados por desarrollarse en una estructura productiva desequilibrada y periférica como la argentina. Esta situación conlleva a la necesidad de regulación de la ESS mediante una institucionalización que le permita consolidarse y expandirse (Blasco y García, 2017, p.180).

Dentro del área de estudio (Área Metropolitana del Gran Resistencia y provincia de Corrientes) han existido muchas experiencias incluidas dentro del universo de la economía social que venían encarando sus actividades desde el detonante económico y social del 2001 sin un reconocimiento legal. En este sentido, uno de los caminos tomados fue la institucionalización del sector, cuestión que desembocó en la sanción de leyes específicas en la temática. Primero fue la provincia de Corrientes, que en el año 2007 aprobó y puso en vigencia la Ley $\mathrm{N}^{\circ} 5774$ que, para apoyar al sector, creó el "Programa de Promoción del Microcrédito para el desarrollo de la economía social” en el ámbito de la Secretaría de Desarrollo Humano, dependiente del Ministerio de Desarrollo Social provincial y que a su vez contiene a la Dirección de Comercialización de Economía Social. Otro impulso importante para el sector fue el lanzamiento de la Marca Colectiva "Hecho en Corrientes", surgida del Programa provincial Sello Correntino (Ley $\mathrm{N}^{\circ}$ 6478) del Ministerio de Industria, Trabajo y Comercio de Corrientes, con el objetivo de identificar, distinguir y potenciar a la industria local.

Por otra parte, en la provincia del Chaco en el año 2014 entró en vigencia la Ley № 7480, mediante la cual se creó el "Sistema de Promoción y Desarrollo de la Economía Social y Solidaria"; siendo la Subsecretaría de Economía Social la encargada de suministrar apoyo a los emprendedores a través de líneas de microcrédito, capacitaciones y talleres. Se otorga la Marca Colectiva "Chaco Produce" a quienes desarrollen una actividad productiva, utilizando materia prima regional y buscando el reconocimiento distintivo por parte de los consumidores.

\section{Resultados}

Los resultados presentados en este trabajo responden al abordaje de diferentes experiencias reconocidas como organizaciones de la economía social, relevadas e investigadas con un grupo de alumnos con quienes se trabajó durante todo el proceso de investigación arribando a la evidencia empírica de los casos específicos que se mencionan en este apartado. En ese sentido, la consideramos como una experiencia enriquecedora dado que, por un lado, evidencia la comprensión teórica del concepto 'economía social' y cómo ello influyó en la elección del caso acerca del cual se propuso indagar. Por otro lado, el caso en sí mismo es abordado como una experiencia concreta, relevante, que visibiliza la trama de relaciones y acciones que sustentan su lógica de funcionamiento.

Dado el carácter exploratorio asumido en este texto reconocemos que la verdadera dimensión de cada organización aparece desdibujada por el tratamiento sintético y descriptivo de cada una de ellas, aún así se cumple con el objetivo de este trabajo que está orientado a comunicar y evidenciar casos específicos de economía social con las particularidades y formas de funcionamiento propios de cada una.

\subsection{Organizaciones y prácticas de Economía social}

En general, las organizaciones refieren a diferentes modalidades entre las que se pueden mencionar las siguientes: pequeña o mediana empresa -economía social capitalizada según Roitman (2015)-, microemprendimiento familiar, emprendimientos de carácter unipersonales, familiares o asociativos (en algunos casos con financiamiento), ferias populares que comercializan productos de la agricultura familiar, cooperativas, empresas recuperadas por trabajadores, movimientos sociales y sus actividades productivas, mutual -economía social de subsistencia según Roitman (2015)-, fundación, entre otras.

A continuación presentamos, en forma muy resumida, un listado de 22 actividades enmarcadas en la categoría 'economía social' describiendo sus principales características.

1. CRAliS: comenzó como un emprendimiento familiar y con el tiempo se transformó en una pequeña empresa. Se dedica a la producción y venta de alimentos congelados, medallones de verduras y legumbres y tartas, elaborados con una amplia variedad de vegetales, agregando valor a la actividad agropecuaria local. Su fábrica y punto de venta se encuentra en pleno 
centro de la ciudad de Resistencia (Chaco). Su nombre hace alusión al acrónimo de "CorrientesResistencia Alimentos Saludables"; plantea el cooperativismo productivo para ampliar el mercado e insertarse en cadenas de supermercados. Actualmente la producción es de entre 25.000 y 30.000 medallones por mes.

2. La Cruz emprendimiento productivo hortícola: el mismo se localiza en la localidad de La Cruz (Corrientes) en el que un grupo de 10 familias desarrollan sus actividades en un terreno situado en el Paraje Isoquí de esa localidad, donado por la Municipalidad. Allí mismo, todas éstas familias han construido en forma mancomunada, tres invernaderos de una superficie de 300 m2, más $150 \mathrm{~m} 2$ de huerta al aire libre gracias a la ayuda del Programa ProHuerta, del Ministerio de Desarrollo Social de la Nación y del INTA, de la Municipalidad de La Cruz, proveyendo los insumos necesarios para la colocación de un sistema de riego por goteo. Las familias fueron capacitadas por equipos profesionales para favorecer la producción hortícola y mejorar la siembra, el cuidado y la cosecha de los cultivos. Todo esto les permitió producir, dentro del predio ocupado, una gran diversidad de hortalizas para el autoconsumo y para la comercialización de excedentes en ferias de la ciudad.

3. Chaco Frutal: emprendimiento asociativo que nació en el año 2013 como consecuencia de un proyecto de Extensión Universitaria y vinculación comunitaria denominado "Universidad, Estado y Territorio", elaborado y ejecutado en forma conjunta desde la Oficina de Gestión Metropolitana del INTA con la Cátedra de Sociología de la Facultad de Relaciones Laborales. Con el desarrollo del proyecto se promocionaron estrategias asociativas para el fortalecimiento de emprendimientos socioproductivos de la agricultura familiar. En ese marco quedó conformado "Chaco Frutal" que hoy en día congrega a integrantes de 6 familias de la localidad de Puerto Vilelas (Chaco). Se dedican a la elaboración de conservas y dulces de mamones y naranjas, también mermeladas con frutas orgánicas obtenidas por los productores de la zona. Los productos se comercializan con el tradicional mecanismo del "boca en boca" y en algunos comercios de la zona. Además de recibir el apoyo del gobierno del Chaco y del INTA, el emprendimiento fue beneficiado en la primera convocatoria de los Proyectos Especiales de Pro-Huerta, enmarcado en la línea Valor Agregado, donde obtuvieron equipamiento para aumentar el volumen de producción. Gracias a ello se logró duplicar la misma y pasar de elaborar entre 100 y 120 frascos por semana a 250. Con el tiempo, Chaco Frutal obtuvo el sello de calidad en origen bajo la marca "Chaco Produce". Esta distinción garantiza que las conservas dulces elaboradas sean con materia prima y mano de obra chaqueña, al tiempo que cumplen con los trámites tributarios y habilitaciones correspondientes.

4. Textil Irupé: emprendimiento productivo de rama textil que nació a principios del año 2018, cuando GenerAr, una asociación civil sin fines de lucro del Barrio Irupé de la ciudad de Corrientes decidió darle a la organización una rama productiva. Sus integrantes comenzaron a investigar sobre fuentes de financiamiento hasta encontrarse con el Programa Nacional "Manos a la Obra", del Ministerio de Desarrollo Social de la Nación destinado a la adquisición de maquinarias y herramientas para cooperativas de trabajo. Presentaron su proyecto productivo y fueron aprobados, logrando con esa ayuda la compra de máquinas de coser para la creación de un taller textil. Actualmente, son 12 las personas que trabajan en este emprendimiento textil que funciona en el Centro Integrador Comunitario del barrio, se dedican a la confección de juegos de sábanas, toallas, remeras de algodón y bolsas de friselina, entre otros productos. Todo lo que se elabora en este emprendimiento textil lleva el sello "Hecho en Corrientes", lo que denota el acompañamiento por parte del Ministerio de Industria, Trabajo y Comercio de la provincia para que sus productos sean de calidad.

5. Vivero Mundo Verde: emprendimiento familiar integrado por 6 personas (4 miembros de la familia y la colaboración de dos empleados más) ubicado sobre Ruta Nacional №12, Km 1018, localidad de Riachuelo (Corrientes). Poseen 9 invernaderos en los que trabajan en la producción de plantas, plantines, arbustos, y accesorios de jardinería. El día de trabajo se organiza de tal manera que la producción se realiza por la tarde y la comercialización por las mañanas, las que son efectuadas en diferentes ferias que establece la municipalidad de Corrientes (Parque Mitre, Plaza de la Cruz, Plaza Juan de Vera, entre otros lugares). No reciben ningún subsidio del Estado, sólo son monotributistas de la categoría más baja y la ganancia obtenida en el emprendimiento es el único ingreso de la familia.

6. Productores Apícolas San Cosme: es un emprendimiento apícola propiedad de una familia que reside en la ciudad de San Cosme (provincia de Corrientes). Iniciaron sus actividades en el año 2014 con el objeto de producir miel pura para consumo propio, con el tiempo 
adquirieron experiencia y al perfeccionarse en el rubro decidieron comercializar el producto, aprovechando la demanda local de miel 100 \% pura tan difícil de conseguir en el mercado. El emprendimiento tuvo un crecimiento importante, ya que al inicio solo contaban con 4 colmenas y en la actualidad el número aumentó a más de 30 colmenas propias. El apiario se encuentra en un terreno familiar sobre Ruta Provincial $\mathrm{N}^{\circ}$ 9, allí realizan la actividad principal que es la extracción de miel y en temporada también se dedican a la recolección de polen (reúnen todos los requisitos para obtener una miel ecológica). En total son 8 personas las que trabajan desarrollando las actividades (matrimonio con sus tres hijos y otros 3 familiares), todos participan colaborativamente, reparten sus roles entre las manipulaciones con los enjambres de abejas y el exprimido de la miel. Los productos que obtienen, tanto la miel como el polen, se comercializan en envases plásticos con tapa hermética que los compran a una empresa de otra provincia y los reciben por encomienda. Efectúan las ventas por kilogramos a los clientes minoristas que provienen de diferentes clases sociales, pero, según señala el entrevistado, principalmente son las personas mayores las que más consumen dado que se considera un producto beneficioso para la salud. Este emprendimiento no recibe ayuda del Estado, todos los materiales son financiados por la familia a través de los ingresos percibidos por las ventas, que se invierten en cajas, ceras y demás herramientas necesarias. El emprendimiento no genera ingresos suficientes como para solventar los gastos del grupo familiar, se trata de una actividad complementaria que ayuda a cubrir algunas necesidades básicas, no obstante la familia tiene expectativas positivas a mediano y largo plazo.

7. Granja Porá: microemprendimiento familiar situado en la periferia de la ciudad de Corrientes que cuenta con una trayectoria de 20 años. Forman parte de una Asociación Civil llamada "Feria y mercados populares". El Estado no les otorga ningún subsidio, solo les brinda el espacio físico para su instalación en lugares de recreación popular (Parque Mitre, Plaza Vera, Plaza Torrent, Plaza de la Cruz), donde pueden colocar banderas con auspicio de la Municipalidad de Corrientes. En ocasiones se capacitan gratuitamente en el Ministerio de Desarrollo Social de la provincia. Se dedican a la producción y elaboración de miel de abejas, dulces artesanales regionales (mamón, zapallo, naranja, mermelada de frutos rojos), productos salados como quesos criollos, escabeches, pickles. También incorporan variedad de aceites (oliva extra virgen, de coco, de lino, de pepitas de uva), cereales (barritas energéticas, mix de cereales) y jugos de frutas (arándanos, maracuyá y frutos rojos).

8. Senta Lui Nei alimentos azucarados: microemprendimiento familiar surgido en el año 2015 con el propósito de lograr un ingreso a partir de la venta de alimentos en almíbar. El local productivo está radicado en la localidad de Fontana (Chaco) y cuenta también con un punto de ventas en Resistencia (Barrio Los Troncos). En 2017 pudieron acceder a un crédito otorgado por el gobierno provincial que les permitió adquirir una máquina e insumos. El proceso de producción va desde la obtención de la materia prima hasta el envasado al vacío de sus productos. En su máximo funcionamiento ofreció puesto de trabajo a 10 personas ( 8 operarios, 1 ingeniero en alimentos y 1 administrativo); actualmente se encuentra en una fase de estancamiento comercial dado que las ventas no generan la suficiente ganancia.

9. "Cervezas Kosherr": microemprendimiento de cerveza artesanal localizado en la ciudad de Resistencia (Chaco) que surge por iniciativa de un recién egresado en ingeniería en alimentos, quien decide colocarle ese nombre de fantasía, palabra que en hebreo significa "adecuado". La iniciativa está formada por 3 integrantes (dos miembros de la familia y un amigo) que comenzaron sus actividades con capital propio y señalan no haber recibido ningún aporte público. A través de la compra en línea se proveen de los productos necesarios para producir cerveza artesanal de distintos tipos (Porter, Apa, Irish Red y Golden). El proceso de elaboración va desde la molienda, el macerado, la cocción, fermentación y envasado. Se elaboran hasta 10 sabores diferentes y buscan canales de comercialización en eventos familiares, reuniones culturales y con la difusión del boca a boca. Actualmente se encuentran en una fase de experimentación y reconocimiento del mercado.

10. El Rey Del Mate "Los Araujos": es un pequeño emprendimiento familiar que se dedica a la talabartería. Desde hace 12 años ocupa uno de los puestos que se encuentra en el Paseo de Compras en la localidad de Corrientes, por el cual abonan un impuesto municipal. Allí atienden todos los días de 8 a 16 horas; anteriormente estaban en la plaza Cabral junto a los demás puesteros. Su dueño y promotor, Carlos Araujo (quien también se considera un artesano) cuenta con la ayuda de su hijo para elaborar mates de cuero, porta-termos, cintos, maletines, forrados de termos, reparación de mates y reparación en cuero, porta botellas y porta latas. Se dedica a esta actividad desde hace 30 años, sus clientes provienen de todas las clases sociales, 
y admite que le gusta transmitir la cultura popular del mate a turistas de diferentes provincias que visitan su puesto.

11. Artesanías el Tacuaral: microemprendimiento de carácter familiar ubicado en la localidad de Corrientes que surgió luego de la crisis económica y social del año 2001. Realizan artesanías en madera (cuadros, llaveros, porta llaves, etc), grabado y pintura en madera, artesanías con tejidos y fibras vegetales. Los puntos de comercialización son las ferias francas itinerantes que se desarrollan todos los viernes en diferentes plazas de la ciudad. También poseen un puesto fijo en el Paseo de los Artesanos ubicado en la costanera de la ciudad capital, donde trabajan los fines de semana. Dicho espacio fue tramitado en la Municipalidad y deben cumplir con requisitos como por ejemplo libreta sanitaria. No reciben ningún subsidio del Estado, solo fueron beneficiados con dos máquinas de coser que les proveyó el Ministerio de Desarrollo Social.

12. Vivero Gorosito: pequeño emprendimiento relacionado con la producción y comercialización de plantas ornamentales y aromáticas. La encargada, Flavia Gorosito, es una feriante cuyo lugar de producción se ubica en San Cosme (provincia de Corrientes) en un predio de 4 hectáreas, en el que también reside. El lugar físico donde realiza sus ventas es la Plaza Federico Leloir en la localidad de Paso de la Patria. Inició sus actividades por hobby, ya que es hija de un pequeño productor nucleado en la Asociación de Pequeños Productores, donde también es socia. Es profesora de filosofía y la labor que realiza en el vivero constituye su ingreso principal, que le posibilitó el acceso a otro estudio superior como es el Profesorado de Biología.

13. Producción Ensenadita: microemprendimiento familiar dedicado a la producción y comercialización de verduras, quesos frescos, dulces regionales y frutos secos. La encargada, María Acosta, es una feriante que tiene su centro de producción en Paraje Ensenadita, en un predio de 25 hectáreas donde también reside. El mismo está ubicado en el Departamento

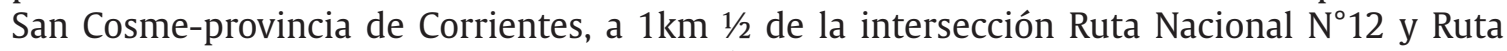
Provincial $\mathrm{N}^{\circ} 6$. La actividad desarrollada allí le sirve para complementar los ingresos de la economía familiar, produciendo tanto para su autoconsumo como para la comercialización. Es una productora que busca ser ecológica y sustentable; y esto se ve reflejado en su lugar de producción, donde solamente utiliza materia orgánica e incluso técnicas naturales para evitar plagas en su producción como la plantación de aromáticas en las cabeceras de sus invernaderos.

14. Cooperativa "Fortaleza": se formó luego de la grave crisis del año 2001, en el que un grupo de 11 familias del barrio Ongay de la ciudad de Corrientes se pusieron como meta encontrar una propuesta laboral propia, dado que la mayoría realizaba trabajos temporarios y otros quedaron desocupados. La iniciativa de estas personas contó con el apoyo del barrio, pues comenzaron "cartoneando" materiales plásticos, cartones y vidrios, para luego realizar la separación, clasificación y comercialización de residuos secos (cartón, papel, botellas/ bolsas plásticas, vidrios, latas, etc). Si bien tuvo un proceso inicial de autoayuda a través de la limpieza y recolección de los materiales para el reciclado, la saturación de los predios de las viviendas o lugares de almacenamiento llegaron a colapsar. Es allí cuando, una vez organizados, recurrieron a las instituciones del gobierno con el objeto de gestionar un lugar físico para seguir con la actividad. Una vez adquirido en comodato el "Galpón" (conocido hoy como Punto Verde) el crecimiento en capacidad de reciclaje fue muy importante, hasta el punto de vender a países vecinos materiales reciclados compactados. El sistema de recolección de los materiales arriba nombrado se da por distintas vías: por los carreros (carro de un eje tirados por caballo) que recorren la ciudad recolectando cartones y demás materiales reciclables, las empresas privadas y públicas que abastecen (a través de convenios firmados), y los puntos verdes localizados en dos zonas estratégicas y comerciales de la ciudad. Este último, fue planificado y proyectado por la cooperativa, quienes lograron inversión de las entidades privadas para su concreción. En función de ello muchas familias, hoy más organizadas, recolectan materiales reciclables, realizan el proceso de reciclaje y compactación en el "Galpón" y venden a fábricas nacionales y extranjeras, logrando así un salario que les permite satisfacer las necesidades básicas de sus familias.

15. Cooperativa Apícola "Eireté Porá": se encuentra en la localidad de Loreto, provincia de Corrientes. Surge por iniciativa de unos pocos vecinos aficionados a la apicultura quienes sostienen todas las actividades con un esfuerzo mancomunado. Cuenta con seis miembros activos, quienes renuevan su banca al 50 \% en la próxima asamblea en los meses de diciembre. Todos son de la misma localidad y llevan a cabo las tareas de producción y administración. Elaboran productos orgánicos porque evitan la utilización de productos tóxicos, dando así una mejor calidad de 
miel. Se comercializa fundamentalmente en Loreto, Itá Ibaté, Ituzaingó, San Miguel, General Paz y San Isidro y Olivos (Buenos Aires). Cabe destacar que con la colaboración del Ingeniero Abelleira y de la Fundación Solidaridades, la producción de miel loretana ha llegado a Alemania, donde la calidad fue evaluada y obtuvo el sello de producto óptimo, adquiriendo cerca de 100 frascos anualmente.

16. Cooperativa de Trabajo “Unión Saladeña” Ltda. Se encuentra ubicada en la localidad de Saladas (Corrientes). Inició sus actividades en junio del año 1993 con el nombre Pindapoy S.A. pero como consecuencia de la crisis del 2001 tuvo que despedir a sus 93 empleados, quienes recibieron como parte de pago de la indemnización el sector empaque de la empresa. Con el tiempo éstos decidieron recuperar la misma. Los asociados iniciales contaban con experiencia anterior en la empresa Pindapoy S.A, actualmente quedan 86 empleados trabajando en la planta, se dedican a las tareas inherentes al empaque de frutas (naranja, mandarina, pomelo y limón) y hortalizas, prestación de servicios de cámara de frío y maduración, fabricación de cajones y embalajes, entre otras. La administración de la Cooperativa la realiza el Consejo de Administración elegidos según Asamblea General Ordinaria. Actualmente reciben aportes de la Federación de Cooperativas de Corrientes Ltda., entidad de $2^{\underline{0}}$ Grado a la cual se encuentra adherida.

17. Cooperativa Utrasa: la Cooperativa Unión de Trabajadores Sanluiseños se ubica en la localidad de San Luis del Palmar (Corrientes), es una empresa autogestionada dedicada a la fabricación de calzado que apunta a construir un espacio de trabajo horizontal, basado en el esfuerzo, el compromiso y la responsabilidad de sus socios, aportando al desarrollo de la comunidad. Se trata de una Empresa Recuperada y autogestionada por sus propios trabajadores a partir de la quiebra de la entonces denominada Gatic S.A. el 26 de octubre del 2004, donde los empleados lograron la tenencia de la planta conformando de este modo la cooperativa Utrasa, que se propuso garantizar el cuidado de todas las instalaciones con un seguro integral. Su crecimiento actual se debe a que la mano de obra es calificada, la infraestructura adecuada y se cumplen con los requerimientos laborales y todos los compromisos asumidos, al punto de constituirse en la principal fuente laboral de dicha localidad. Está compuesta por 222 socios, cada uno con un rol distinto y distribuidos en diez sectores. La Actividad/rubro de esta cooperativa está relacionada con calzados, fabricación de zapatillas, botas y zapatos de seguridad para empresas. Las marcas reconocidas con las que trabaja son Maincal, Ringo, Merrel, Plumitas, Jaguar y Lemarroc. Se busca promover y fortalecer espacios de colaboración a través de la donación de toneladas de descartes que se vuelcan a otros 56 emprendimientos, esto les permite disminuir la cantidad de residuos y el impacto ambiental, y fomentar la reutilización de los materiales para su transformación en bienes de utilidad como estrategia de fortalecimiento a la actividad emprendedora.

18. Cooperativa MTD 12 de junio (Movimiento de Trabajadores Desocupados): este movimiento social de trabajadores desocupados denominado 12 de junio conformó una cooperativa de trabajo que surgió en el año 2009 en la localidad de Barranqueras (Chaco). Está formada por más de 100 familias de esa misma localidad y de Puerto Vilelas que se dedican a la construcción, reforma y reparación de viviendas residenciales, departamentos y albergues para niños y ancianos. En una entrevista efectuada a su líder o referente, este afirmó que: "estamos agradecidos con el gobierno del Chaco, con el Programa Argentina Trabaja, con el Instituto de Vivienda y la Municipalidad de Resistencia, que en conjunto nos suministran herramientas de trabajo, ropa para los compañeros y se encargan de las cuestiones territoriales para la construcción de viviendas". Señala que permanentemente estrechan vínculos con otras organizaciones con las que intercambian experiencias y lazos de solidaridad en las luchas. En ocasiones, los jóvenes que integran este movimiento social pueden acceder al sistema de becas que les permite completar sus estudios y capacitarse para obtener una mejor inserción en el ámbito laboral. Suelen contar con la ayuda del gobierno y otros organismos que les suministran herramientas de trabajo y vestimenta adecuada.

19. Cooperativa "El Líder Supermercado": es un supermercado con estructura de trabajo cooperativo ubicada en el Barrio General San Martín de la localidad de Ituzaingó (Corrientes) que nació a partir de la quiebra y posterior cierre de la empresa preexistente, dejando a modo de indemnización el fondo de comercio a sus empleados (en la actualidad socios) en el año 2001. Esta Empresa Recuperada funciona como organismo de autogestión con participación democrática de los socios, quienes toman, a partir de esta participación social, las decisiones referidas a la distribución de los ingresos que se generan con la venta de los productos que ofrecen en el mercado. Se organizan a través de un Consejo Administrativo conformado por 
un presidente, un secretario, un tesorero y dos síndicos encargados del bloque societario. La cooperativa ofrece la oportunidad de asociar de forma automática a las personas que se suman a la empresa, ofreciéndoles desde el comienzo de sus actividades algunos beneficios como cobertura de obra social (con la posibilidad de agregar un familiar más), descuentos en las compras de mercaderías y productos, cobertura del pago del monotributo, etc. Funciona como núcleo independiente del Estado desde su reactivación, esto implica el trabajo societario sin un sistema de subvención económica estatal de ninguna escala (local, provincial o nacional). Actualmente, el Líder Supermercado cuenta con 32 socios que ocupan puestos específicos ofreciendo productos de la canasta familiar, algunos son traídos del mercado central correntino, como frutas y verduras, otros son de la zona como es el caso de la carne vacuna; asimismo se encargan de elaborar el panificado que abastece el consumo interno de la ciudad de Ituzaingó y sus alrededores.

20. AMUDOCH: La Asociación Mutual de Docentes de la Provincia del Chaco es una institución sin fines de lucro que surgió por iniciativa de un grupo de docentes, que ostentando los valores del mutualismo, se reunieron y formaron primero una comisión provisoria en 1982 y luego a través de una asamblea constitutiva dieron origen a esta asociación mutual, que contó con dos guías fundamentales desde el principio: el estatuto social y la solidaridad. Tiene su sede central en la ciudad de Resistencia (Chaco) y sucursales en 23 localidades del interior provincial. En la actualidad tiene aproximadamente 16.000 asociados docentes de diferentes niveles educativos de la provincia, quienes cuentan con servicios como farmacia mutual, óptica, compras en comercios adheridos, salones para eventos, camping, y turismo entre otros.

21. "Feria Popular San Cosme, Paso De La Patria”: la Feria Franca es una organización que cuenta con sus habilitaciones pertinentes, la misma se ha consolidado en la última década y media, respondiendo principalmente a una demanda provocada por la crisis de las capacidades del sistema económico para integrar a la sociedad a desocupados y excluidos. El trabajo de los feriantes correntinos está acompañado por diferentes instituciones como el INTA, el Instituto de Cultura Popular (INCUPO), la Subsecretaría de Agricultura Familiar de la Nación, municipios, y organismos del gobierno provincial, que otorgan las habilitaciones bromatológicas para su funcionamiento. Esta feria popular se inició en el año 2000 como centro de comercialización en Paso de la Patria, ubicado en la esquina 25 de mayo y Buenos Aires. En sus inicios sumaban un total de 30 familias que se dedicaban a la venta, todas nucleadas en la Asociación de Pequeños Productores de San Cosme. Actualmente el espacio físico es en la Plaza Dr. Federico Leloir, donde solo trabajan los fines de semana un total de 5 familias feriantes que ofrecen sus productos, que van desde una gran variedad de frutas y hortalizas, miel, productos de granja, dulces regionales, productos artesanales, panificados, quesos, frutos secos y plantas ornamentales, entre otros.

22. Fundación Hendú: es una institución sin fines de lucro cuyo significado en guaraní es "entender, escuchar, oír", está integrada por 9 personas y 3 voluntarios permanentes y se localiza en el Barrio Independencia de la ciudad de Corrientes. Recibe el apoyo del gobierno provincial a través de la Subsecretaría de Trabajo, de este modo se encargan de dictar cursos de capacitación gratuitos (con material incluido aportado por el Estado) sobre técnicas de aprendizaje para la confección de bijouterie y cotillón destinado a mujeres y hombres de bajos recursos. Los mismos se van adaptando al calendario anual para responder y atender a las demandas específicas y a festividades generales y locales. Desde la fundación también se fomenta la práctica del fútbol y ayudan a los niños a realizar los viajes de encuentro de los partidos ya que en muchos casos éstos no disponen de dinero para costear gastos.

\subsection{Las formas organizativas de los casos estudiados}

A grandes rasgos se observa que algunas de las experiencias presentadas heredan una parte del legado del histórico movimiento cooperativista de fines del siglo XIX y principios del XX, aunque constituyen prácticas nuevas, ajustadas a los tiempos actuales. Algunas de ellas poseen muchos trabajadores, otras cuentan con personal más reducido lo que lleva a ocuparse tanto de la administración como de la producción.

En relación al crecimiento y diversificación de las otras experiencias presentadas, se advierte que, en ciertos casos han estado vinculadas a momentos de crisis socio-económica (como la del 2001) situación que para algunos de ellos ha sido el detonante para la emergencia de este tipo de prácticas, algunas de carácter asociativo, otras familiares. 
En general, los motivos que movilizan estas construcciones sociales van desde tratar de producir y comercializar lo necesario para subsistir (excepto los casos sin ánimo de lucro presentados como la Fundación Hendú y la Mutual Amudoch) hasta el deseo mismo de alterar estructuras económicas imperantes.

En el caso particular de las actividades o emprendimientos de carácter tanto familiares como asociativos, se aprecia la recuperación de habilidades y capacidades de las personas, en tanto han favorecido el desarrollo de la creatividad y la autonomía en el trabajo autogestivo con poder de decisión (por ejemplo "El Rey del Mate Los Araujos", vivero Gorosito, artesanías "El Tacuaral”, cervecería artesanal Kosherr") que constituyen unidades de subsistencia cuyo principal objetivo es la autogeneración de empleo.

En el caso particular de las ferias francas son espacios de intercambio local que permite la recomposición de las economías familiares de los integrantes, a la vez que impulsa la revalorización personal de las personas, una mayor intensidad de lazos sociales y la dinamización de la producción.

Este conjunto de prácticas demuestra la complejidad y variedad que la conforma y ello nos plantea la necesidad de encontrar algún elemento aglutinador que facilite su análisis y revisión. Como lo señaláramos anteriormente, la trama de relaciones y acciones que sustentan su lógica de funcionamiento son esenciales para "ubicarla" o situarla en un determinado grupo construido desde la teoría. En ese sentido, esbozamos lo que podría considerarse un elemento aglutinador: el carácter colectivo o individual de la iniciativa, la figura jurídica que los nuclea y el grado de vinculación con el Estado.

A grandes rasgos podríamos agrupar las diferentes experiencias anteriormente mencionadas en:

\subsubsection{Iniciativas Colectivas:}

a. Personas jurídicas por su grado de formalidad

- Cooperativas -(Empresas Recuperadas por sus trabajadores): se incluyen aquí varias experiencias que conforman asociaciones autónomas que constituyen una empresa de propiedad conjunta y democráticamente gobernada, los ejemplos que se incluyen en este trabajo han surgido luego de un contexto de crisis económica y social, en el que los mismos trabajadores han recuperado la empresa para conservar su fuente laboral; es el caso de la cooperativa Utrasa, ubicada en el pequeño poblado de San Luis del Palmar (Corrientes) que cuenta con 222 socios y se dedican a la fabricación de calzados, representa por tanto la principal fuente laboral de esa localidad; otro caso es la cooperativa Unión Saladeña, de Saladas (Corrientes) que cuenta con 86 socios que se dedican al empaque de frutas y hortalizas, y a la fabricación de cajones y embalajes. Finalmente puede citarse como ejemplo a la cooperativa "El Líder supermercado" ubicada en la ciudad de Ituzaingó (Corrientes). Los tres ejemplos citados se encuentran inscriptos en el INAES (Instituto Nacional de Asociativismo y Economía Social) y funcionan actualmente bajo el sistema cooperativo, con resultados positivos en lo laboral y rentabilidad. Sus empleados se encuentran formalizados debido a que gozan de beneficios como obra social y realizan los aportes correspondientes.

- Mutual y Fundación: son entidades con fines sociales y sin ánimo de lucro, dentro de esta categoría estarían la Fundación Hendú (que recibe apoyo del Estado) y la Mutual Amudoch, que nuclea a miles de docentes de la provincia del Chaco.

b. Grupos asociativos legitimados socialmente:

- Movimientos sociales: en este trabajo se hace hincapié al movimiento social "MTD 12 de Junio", cuyos integrantes reciben ayuda por parte del Estado pero la misma no es de carácter monetaria o crediticia, sino a través de herramientas de trabajo y vestimenta para ejecutar la construcción y reparación de viviendas.

- Ferias francas (con vínculos con el gobierno local): constituyen espacios donde los pequeños productores pueden comercializar su producción. En este sentido, cada municipio habilita un espacio físico para tal fin. Este espacio oficial de intercambio local permite la recomposición de las economías familiares de los integrantes, a su vez que impulsa la revalorización personal de ellos, una mayor intensidad de lazos sociales y la dinamización de la producción. Un ejemplo es la feria popular de San Cosme, que atiende en la localidad de Paso de la Patria, donde las familias, además de vender todo tipo de frutas y hortalizas también ofrecen panificados y una amplia variedad de plantas. Lo 
mismo sucede con los productores de Ensenadita (San Cosme, Corrientes) y los integrantes del emprendimiento familiar "Granja Porá" que se destacan en la elaboración de miel de abejas, dulces regionales, productos salados, variedad de aceites, cereales y jugos de frutas, y los ofrecen en diferentes plazas de la ciudad capital de Corrientes. Efectivamente, esta situación genera un tejido más denso de relaciones con el gobierno local, quien a través de la Dirección de Bromatología se encarga de fiscalizar la sanidad de los productos regionales ofrecidos.

\subsubsection{Iniciativas Individuales/Familiares:}

a. Empresa familiar vía financiación: aquí se incluye a la empresa Cralis, que se dedica a la producción y venta de productos congelados y medallones de verduras. Han accedido a microcréditos para emprendedores y a créditos del Ministerio de la Producción de la Nación para equiparse por completo. Actualmente la empresa lleva la marca colectiva "Chaco Produce".

b. Microemprendimientos de carácter informal sin la presencia del Estado: incluye algunas de las experiencias de carácter tanto familiares como asociativos, en la cual se aprecia la recuperación de habilidades y capacidades de las personas, en tanto han favorecido el desarrollo de la creatividad y la autonomía en el trabajo autogestivo con poder de decisión (por ejemplo "El Rey del Mate Los Araujos", vivero Gorosito , artesanías "El Tacuaral”, cervecería artesanal Kosherr", familia Romero productores apícolas de San Cosme) constituyen unidades de subsistencia cuyo principal objetivo es la autogeneración de empleo. En esos casos, tanto las personas como las familias pusieron en marcha sus iniciativas sobre la base del esfuerzo propio y de su trayectoria y saberes, donde los principales inconvenientes en su desenvolvimiento se vinculan a la carencia de financiamiento y en algunos casos de locales comerciales propios (artesanías y cervecería).

c. Emprendimientos asociativos formalizados con vínculos con el Estado: se citan las experiencias de carácter asociativo como "Chaco Frutal", que ha surgido a partir de la estimulación de agentes externos (proyecto de Extensión Universitaria y vinculación comunitaria) y que ha contado con la promoción estatal desde el INTA y el Programa ProHuerta para mejorar las condiciones de vida de sectores excluidos, a partir del involucramiento de los integrantes en un proyecto y la autogestión del mismo. Otro caso es el "emprendimiento hortícola de La Cruz" (Corrientes) en el cual diez familias fueron beneficiados con la donación de un terreno por parte de la municipalidad local para desarrollar sus prácticas y del Gobierno Nacional a través de diferentes programas para implementar sus proyectos productivos. Finalmente destacamos en esta categoría al emprendimiento "Textil Irupé", que contó en sus inicios con el apoyo del programa Manos a la Obra y su producción actual lleva el sello "Hecho en Corrientes", lo que denota el acompañamiento por parte del Ministerio de Industria, Trabajo y Comercio de dicha provincia.

A nuestro modo de ver, creemos necesario que las experiencias se puedan financiar, abastecer, hacer circular su producción, perfeccionarse tecnológicamente y educar a sus miembros en el intercambio con otros emprendimientos solidarios. Ahora bien, para que el Estado aporte a la expansión y profundización del subsistema de economía social se requiere que las fuerzas políticas en el gobierno tengan un proyecto en tal sentido, y superar las tendencias cortoplacistas y clientelistas (Coraggio, 2013).

Actualmente, la promoción de las prácticas de economía social se encuentra, en parte, institucionalizada, aunque tanto en Chaco como en Corrientes pareciera ser un correlato de las estrategias nacionales de inserción o reinserción de sectores vulnerables. En épocas donde la coyuntura muestra un significativo deterioro del empleo y el salario, puede observarse que la economía social y solidaria es concebida por los decisores de políticas públicas como instrumento de apoyo al auto-empleo, y en ocasiones como un campo de promoción de una economía alternativa, que trasciende la estrategia de la sobrevivencia. Por eso creemos fundamental la existencia de un Estado presente, no sólo con la entrega de créditos o herramientas para iniciar proyectos productivos, sino también brindando capacitación y guía permanente, donde se garantice el trabajo asociado y se facilite el acceso al mercado, por tanto, debe trabajar en forma conjunta con las organizaciones, regulando y fomentando las economías regionales en un proceso de construcción colectiva, con el objeto de que, en algún momento los trabajadores puedan lograr estabilidad y formalización en la búsqueda de una reorganización más igualitaria de la economía. 


\section{Conclusiones}

En este trabajo intentamos mostrar algunas de las particularidades con que se presenta la economía social y solidaria tanto en la ciudad de Resistencia como en algunas localidades de la provincia de Corrientes. Lo expuesto hasta aquí intenta mostrar que el proceso de transición hacia otra economía exige, por un lado, articular y reconocer diversas formas de organización y acción dirigidas a resolver las necesidades, y por otro, a promover sistemas que vinculen producción, reproducción y desarrollo de las capacidades y realizaciones de los trabajadores.

Coincidimos con Mutuberría Lazarini (2008, p.25) en que "las experiencias enmarcadas en el campo de la economía social responden a todas aquellas formas que en su funcionamiento contestan y cuestionan la lógica de desarrollo capitalista". En este sentido, y como consecuencia de la exclusión generada por varias décadas de políticas neoliberales implementadas en el país y en nuestra región, han surgido una heterogeneidad de prácticas que nacieron a partir de diferentes situaciones y problemas, y que han desarrollado estrategias de supervivencia teniendo como motor principal a la organización de la sociedad en base al trabajo para la reproducción de la vida, en detrimento a la acumulación del capital. Muchas de esas nuevas experiencias comenzaron a desarrollar actividades dinamizadas por la reciprocidad y solidaridad como elementos articuladores de los procesos de producción, distribución, consumo y acumulación, muy diferentes al del modelo dominante.

En relación a lo anterior, compartimos las ideas de Coraggio (2014b), quien afirma que "la economía social surge como respuesta a la exclusión y vulnerabilidad generada por las políticas económicas de mercado, por lo tanto, debe ser considerada como un punto de partida para la construcción de una alternativa sistémica que requiere de otro Estado y de otros Sujetos".

En este sentido, creemos que las experiencias de economía social que han sido incluidas en este artículo -cooperativas, microemprendimientos, fábricas recuperadas, artesanos, agricultores familiares, mutual, fundación-, han mostrado y muestran preferentemente un perfil de trabajo asociativo orientado a la sobrevivencia en tiempos de crisis. En algunos casos surgieron de forma autogestionaria a partir del desempleo provocado por la reestructuración productiva y la reforma estatal y de los mercados de los años 90 , así como también de la crisis económica del 2001. En otros, fueron promovidas o sostenidas por planes sociales y programas de emprendimientos productivos y desarrollo local, centrados en la población vulnerable. En todos los casos se resalta la valoración de cada una de las iniciativas en la búsqueda activa de nuevos escenarios y el reconocimiento social y estatal de un cambio necesario en la jerarquía de derechos en favor de la vida y el trabajo. Cada uno de ellos constituye una propuesta y una apuesta a la democratización económica, lo cual requiere de otro tipo de relación entre sujeto/s y "políticas". Un interrogante planteado sería si las diferentes experiencias presentadas son capaces de asumir plenamente la construcción de otra economía, para ello deberían contrarrestar las contradicciones de un sistema que hoy más que nunca atraviesa una crisis de legitimidad y de racionalidad en sus propios términos.

Para finalizar, solo queda afirmar que la economía social tiene un motor que es la organización social, y es la que reconstruye el tejido social para la transformación. Busca transformar la realidad rescatando y fortaleciendo saberes, prácticas y valores como la dignidad, la equidad, la inclusión y la solidaridad, generando comunidades organizadas que sean artífices de su destino.

\section{Referencias bibliográficas}

Arroyo, D. (2006). Hacia políticas sociales integrales de inclusión" En Ministerio de Desarrollo Social: Foro Federal de Investigadores y Docentes. La Universidad y la Economía Social en el Desarrollo Local. $3^{\circ}$ Encuentro, Buenos Aires

Battisti Telles, L.; Marcuello Servós, C.; Messias Bittencourt J.V. (2020). Las perspectivas Latinoamericana y Europea de la Economía Solidaria. REVESCO. Revista de Estudios Cooperativos, 134, e69171. doi: https://dx.doi.org/10.5209/reve.69171

Borge, D. y Li, F. (2015). Economía social, economía solidaria y economía laboral: un abordaje comparativo desde sus perspectivas conceptuales. IX Congreso Internacional Rulescoop. Recuperado de: http:// sedici.unlp.edu.ar/bitstream/handle/10915/50006/Documento_completo.pdf?sequence=1

Blasco, L. y García, A. (2016). Economía social en construcción. Perspectivas y demandas sociales en la legislación reciente (Argentina, 2003-2015). Revista IDELCOOP. Instituto de la CooperaciónFundación de Educación, Investigación y Asistencia Técnica, (219), 216-239.

Blasco, L. y García, A. (2017). Economía social y solidaria y agenda pública: alcances, actores y objetivos en experiencias provinciales de argentina a principios de siglo XXI. SaberEs, 9(2). 177-195

Borzaga, C., Salvatori, G. y Bodini, R. (2017). La Economía Social y Solidaria y el Futuro del Trabajo. Euricse. 
Documento de trabajo para la OIT/ Oficina Internacional del Trabajo. - Ginebra: OIT, 2018. Recuperado de: http://www.ruess.com.ar/sites/www.ruess.com.ar/files/adjuntos/la-ess-y-el-futuro-del-trabajooit-2017.pdf

Cardozo, L; y Jurado, E. (2016). La cuestión espacial en la economía social y solidaria: una lectura de procesos cooperativos a partir de estudios geográficos. Revista SaberEs, 8(1). 23-42.

Coraggio, J.L. (2002). La Economía Social como vía para otro desarrollo social. Recuperado de: http:/l biblioteca.municipios.unq.edu.ar/modules/mislibros/archivos/laeconomia.pdf

Coraggio, J.L. (2013). Tres corrientes en la EES. Temas $N^{\circ} 75$. Julio-septiembre 2013. Disponible en: https:// base.socioeco.org/docs/descargar_articulo_0.pdf

Coraggio, J.L. (2014a). La presencia de la Economía Social y Solidaria y su institucionalización en América Latina. Documento Ocasional 7, Potencialidades y Límites de la Economía Social y Solidaria, UNRISD. Recuperado de: http://www.unrisd.org/80256B3C005BCCF9/ search/7A2E9D246F8B55B2C1257CF900428C90?OpenDocument

Coraggio, J.L. (2014b). Los sentidos de la economía social. En Revista Voces en el Fénix $N^{\circ}$ 37. La estrategia del caracol. Recuperado de: https://www.vocesenelfenix.com/content/los-sentidos-de-laeconom\%C3\%ADa-social

Guerra, P. (2006). La Economía de la Solidaridad: o la vuelta de los valores sociales a la economía. Revista Umbrales №168. Recuperado de: https://base.socioeco.org/docs/la-economia-de-lasolidaridadpablo-guerra-uruguay.pdf

Guerra, P. (2010). La economía solidaria en Latinoamérica, Papeles de relaciones ecosociales y cambio global. №110, pp. 67-76.

Herrera Gómez, M. (1998). La especificidad organizativa del tercer sector: tipos y dinámicas. Universidad de Granada. Recuperado de: https://papers.uab.cat/article/view/v56-herrera/pdf-es

Hintze, S. y Deux Marzi, M. (2008). La institucionalidad política de la economía social y solidaria en Argentina. XIII Congreso Internacional del CLAD sobre la Reforma del Estado y de la Administración Pública, Buenos Aires, Argentina. Recuperado de: https://www.economiasolidaria.org/sites/default/ files/Economia_social_y_solidaria_en_Argentina.pdf

Laville, J. L. (2001) “Economia Solidaria, a perspectiva europeia”. Sociedade E Estado, 16(1/2), pp. 57-99.

Morales, Oscar Alberto, Rincón, Ángel Gabriel, \& Tona Romero, José. (2005). Cómo enseñar a investigar en la universidad.Educere, 9(29), 217-225. Recuperado de: http://ve.scielo.org/scielo.php?script=sci_ arttext\&pid=S1316-49102005000200010\&lng=es\&tlng=es

Mutuberría Lazarini, V. (2010). El campo de la Economía Social en debate. En: Alfredo T. García (coord.) Repensando la economía social. Cuaderno de trabajo № 86, 1era ed. - Buenos Aires: Ediciones del Centro Cultural de la Coop. Floreal Gorini, pp. 11-28.

Oxoby, P. (2010). Una aproximación a las divergencias e implicaciones de los distintos abordajes a la Economía Social: países centrales europeos y América Latina. En Otra Economía, IV (6), $1^{\circ}$ semestre, 153-166.

Pastore, R. (2006). Diversidad de trayectorias, aproximación conceptual y pluralidad de proyectos de la Economía Social, en Documento 54 del Centro de Estudios de Sociología del Trabajo. Buenos Aires: Facultad Ciencias Económicas, UBA.

Pastore, R. (2010). Un panorama del resurgimiento de la economía social y solidaria en Argentina. Revista de Ciencias Sociales, 2(18), 47-74

Pastore, R. y Altschuler, B. (2015). Economía social y solidaria en clave de desarrollo socio-territorial en Argentina. Conceptos, políticas públicas y experiencias desde la universidad. En Revista: EUTOPÍA (7), pp. 109-128. Recuperado de: https://revistas.flacsoandes.edu.ec/eutopia/article/view/1689/1330

Perez de Mendiguren, J.; Etxezarreta E. y Guridi Aldanondo, L. (2008). ¿De qué hablamos cuando hablamos de Economía Social y Solidaria? Concepto y nociones afines. XI Jornadas de Economía Crítica. ECO CRI Bilbao

Pérezde Mendiguren,J.C.; Etxezarreta,E.(2015).Sobreel concepto deeconomía socialy solidaria:aproximaciones desde Europa y América Latina. Revista de Economía Mundial, (40), pp. 123-143. Sociedad de Economía Mundial Madrid, España. Recuperado de: https://www.redalyc.org/pdf/866/86641407006.pdf

Razeto, L. (2010) ¿Qué es la economía solidaria? Papeles de Relaciones Ecosociales y Cambio Global, № 110, pp. 47- 52. 
Roitman, R. (2016). De qué hablamos cuando hablamos de economía social?. Marcos Mattar Ediciones, 1era edición revisada, Mendoza, 2016. Recuperado de: https://bdigital.uncu.edu.ar/objetos_ digitales/8617/libro-ess-completo.pdf

Sautu, R. (2005). Todo es Teoría: objetivos y métodos de investigación. 1ª. Edición, Buenos Aires.

Singer, P. (2004). Economía Solidaria” En Cattani, Antonio David; La Otra Economía. Economía Social. Buenos Aires, UNGS/Altamira/OSDE.

Valencia Vasquez, E. (2006). Principios de economía humanista. Economía y Sociedad № 9, enero-junio de 2006. V Encuentro Internacional de Economía. Fundación CIEC. Buenos Aires, agosto de 2005.

Vasilachis de Gialdino, I. (2009). Estrategias de investigación cualitativa. Editorial Gedisa, Barcelona, España.

\section{Agradecimientos}

A los alumnos que formaron parte de este trabajo de indagación invirtiendo su tiempo para recopilar los datos y la información necesaria para desarrollar los trabajos coordinado por el equipo de cátedra.

Tabla 1. Experiencias de economía social y solidaria investigadas por los alumnos.

\begin{tabular}{|c|c|c|}
\hline $\begin{array}{l}\text { EXPERIENCIAS DE ECONOMÍA } \\
\text { SOCIAL }\end{array}$ & ALUMNOS & $\begin{array}{c}\text { CÁTEDRAS } \\
\text { Profesorado y Licenciatura }\end{array}$ \\
\hline $\begin{array}{c}\text { 1.- “Cralis” emprendimiento familiar/ } \\
\text { empresarial }\end{array}$ & $\begin{array}{l}\text { Cáceres, Facundo } \\
\text { Medina, Marcos }\end{array}$ & Geografía Económica y Política General \\
\hline $\begin{array}{l}\text { 2.-“La Cruz" Emprendimiento } \\
\text { productivo hortícola }\end{array}$ & $\begin{array}{l}\text { Campos Ivana } \\
\text { Falcón Griselda } \\
\text { Castro Cristina } \\
\text { Albuquerque María } \\
\text { Cardozo María Elena }\end{array}$ & $\begin{array}{c}\text { Fundamentos económicos y Políticos en } \\
\text { la organización del espacio }\end{array}$ \\
\hline 3.-Chaco Frutal & $\begin{array}{l}\text { López Carolina } \\
\text { López Mariela }\end{array}$ & Geografía Económica y Política General \\
\hline 4.-Textil Irupé & $\begin{array}{c}\text { Cáceres Oreste } \\
\text { Lencinas Miriam } \\
\text { Saucedo Daniela }\end{array}$ & $\begin{array}{c}\text { Fundamentos económicos y Políticos en } \\
\text { la organización del espacio }\end{array}$ \\
\hline 5.-Vivero "Mundo Verde" & $\begin{array}{l}\text { González Eliana } \\
\text { Pared Romina } \\
\text { Soto Andrea } \\
\text { Rodríguez Fredes G. }\end{array}$ & $\begin{array}{c}\text { Fundamentos económicos y Políticos en } \\
\text { la organización del espacio }\end{array}$ \\
\hline 6.-Productores Apícolas San Cosme & $\begin{array}{l}\text { Escalante Lucrecia } \\
\text { Flores Cristian } \\
\text { Quaranta Lorena }\end{array}$ & $\begin{array}{c}\text { Fundamentos económicos y Políticos en } \\
\text { la organización del espacio }\end{array}$ \\
\hline 7.- Granja Porá & $\begin{array}{c}\text { Billordo González Nora } \\
\text { Sotomayor Claudia } \\
\text { Píriz Víctor } \\
\end{array}$ & $\begin{array}{c}\text { Fundamentos económicos y Políticos en } \\
\text { la organización del espacio }\end{array}$ \\
\hline 8.- Senta Lui Nei alimentos azucarados & $\begin{array}{l}\text { Gadea Julieta } \\
\text { Prieto, Camila }\end{array}$ & Geografía económica y Política General \\
\hline 9.- "Cerveza Artesanal Kosherr" & Escobar Ojeda, Javier & Geografía Económica y Política General \\
\hline $\begin{array}{l}\text { 10.-El Rey del Mate -Los Araujos- } \\
\text { artesanos }\end{array}$ & $\begin{array}{c}\text { Andreau Lorelaine Francini } \\
\text { Sebastián } \\
\text { Gómez José Javier } \\
\text { Rodríguez Roberto }\end{array}$ & $\begin{array}{c}\text { Fundamentos económicos y Políticos en } \\
\text { la organización del espacio }\end{array}$ \\
\hline 11.- "Artesanías el Tacuaral” & $\begin{array}{l}\text { Bernal María Silvia } \\
\text { Zalazar Cristian }\end{array}$ & $\begin{array}{c}\text { Fundamentos económicos y Políticos en } \\
\text { la organización del espacio }\end{array}$ \\
\hline 12.- Vivero Gorosito & $\begin{array}{l}\text { Bustamante Andrea } \\
\text { Pertiñez María }\end{array}$ & $\begin{array}{c}\text { Fundamentos económicos y Políticos en } \\
\text { la organización del espacio }\end{array}$ \\
\hline 13.- Producción Ensenadita & $\begin{array}{c}\text { Báez Juan Paulo } \\
\text { Bóveda Iván } \\
\text { Delgado, María } \\
\text { Gorosito, Lucía Belén }\end{array}$ & $\begin{array}{c}\text { Fundamentos económicos y Políticos en } \\
\text { la organización del espacio }\end{array}$ \\
\hline 14.- Cooperativa "Proyecto Fortaleza" & $\begin{array}{c}\text { Báez Juan Paulo } \\
\text { Bóveda Iván } \\
\text { Delgado, María } \\
\text { Gorosito, Lucía Belén }\end{array}$ & $\begin{array}{c}\text { Fundamentos económicos y Políticos en } \\
\text { la organización del espacio }\end{array}$ \\
\hline
\end{tabular}


Bonfanti - Falcón / Experiencias económicas alternativas. Casos de economía social en sectores urbanos del...

\begin{tabular}{|c|c|c|}
\hline 15.- Cooperativa Apícola “Eireté Porá” & $\begin{array}{l}\text { García Rocío } \\
\text { Jara María } \\
\text { Martínez Vanesa }\end{array}$ & $\begin{array}{c}\text { Fundamentos económicos y Políticos en } \\
\text { la organización del espacio }\end{array}$ \\
\hline $\begin{array}{l}\text { 16.- Cooperativa de Trabajo “Unión } \\
\text { Saladeña” Ltda }\end{array}$ & $\begin{array}{l}\text { Godoy Raquel } \\
\text { González Araceli } \\
\text { Pujol Soledad } \\
\text { Quintana Belén }\end{array}$ & $\begin{array}{c}\text { Fundamentos económicos y Políticos en } \\
\text { la organización del espacio }\end{array}$ \\
\hline 17.- Cooperativa Utrasa & $\begin{array}{l}\text { Meza María Mercedes } \\
\text { Rodríguez Alicia } \\
\text { Verón Fermina } \\
\end{array}$ & $\begin{array}{c}\text { Fundamentos económicos y Políticos en } \\
\text { la organización del espacio }\end{array}$ \\
\hline $\begin{array}{l}\text { 18.- Cooperativa MTD (Movimiento } \\
\text { de Trabajadores Desocupados) } 12 \text { de } \\
\text { junio }\end{array}$ & $\begin{array}{l}\text { Lopez Paula } \\
\text { Borja Ballón, Juan Pablo }\end{array}$ & Geografía Económica y Política General \\
\hline $\begin{array}{l}\text { 19.- Cooperativa "El Líder } \\
\text { Supermercado" }\end{array}$ & $\begin{array}{c}\text { Leiva Ramiro } \\
\text { Breard Sergio } \\
\text { Jara Rodrigo } \\
\text { Gayozo Alberto } \\
\text { Flores Armando }\end{array}$ & $\begin{array}{c}\text { Fundamentos económicos y Políticos en } \\
\text { la organización del espacio }\end{array}$ \\
\hline 20.- Amudoch & $\begin{array}{l}\text { Morales Claudio } \\
\text { Martínez Carlos }\end{array}$ & Geografía Económica y Política General \\
\hline $\begin{array}{c}\text { 21.- "Feria Popular San Cosme, Paso } \\
\text { De La Patria" }\end{array}$ & $\begin{array}{l}\text { Báez Juan Paulo } \\
\text { Bóveda Iván } \\
\text { Delgado, María } \\
\text { Gorosito, Lucía Belén }\end{array}$ & $\begin{array}{c}\text { Fundamentos económicos y Políticos en } \\
\text { la organización del espacio }\end{array}$ \\
\hline 22.-Fundación Hendú & $\begin{array}{l}\text { Romero Elsa } \\
\text { Torres María Elena } \\
\text { Yllesca Cecilia }\end{array}$ & $\begin{array}{c}\text { Fundamentos económicos y Políticos en } \\
\text { la organización del espacio }\end{array}$ \\
\hline
\end{tabular}

Fuente: elaboración propia. 